\title{
Effect of Smoking in Cognition
}

Karishma Rajbhandari Pandey ${ }^{*}$, Dipesh Raj Panday ${ }^{2}$, Nidesh Sapkota ${ }^{3}$, Anish Dhami ${ }^{4}$, Akshay Sarraf ${ }^{4}$, Sandeep Shrestha ${ }^{4}$ and Deependra KC ${ }^{4}$

${ }^{1}$ Department of Basic and Clinical Physiology, B.P. Koirala Institute of Health Sciences (BPKIHS), Buddha Road, Dharan, Nepal

${ }^{2}$ Department of Clinical Pharmacology and Therapeutics, B.P. Koirala Institute of Health Sciences (BPKIHS), Buddha Road, Dharan, Nepal

${ }^{3}$ Department of Psychiatry, B.P. Koirala Institute of Health Sciences (BPKIHS), Buddha Road, Dharan, Nepal

${ }^{4}$ P. Koirala Institute of Health Sciences (BPKIHS), Buddha Road, Dharan, Nepal

\begin{abstract}
Introduction: Smokers claim that smoking increases their concentration, alertness, and overall mental performance. On the contrary, evidences point at gradual cognitive deterioration in smokers. Montreal cognitive assessment (MoCA) assesses even mild cognitive impairment.

Objective: To determine and compare the cognitive status in smokers and healthy controls.

Method and Materials: A cross-sectional comparative study was done in 46 apparently healthy male healthscience students (23 smokers and 23 nonsmokers) at Pulmonary Function Lab in the Department of Basic and Clinical Physiology, BPKIHS. Pulmonary function tests (PFT) were measured. For cognition assessment MoCA, which is a set of close ended questionnaire was used. To assess smoking status and MoCA score, Mann Whitney $U$ test was employed and data are expressed in median and IQR. Fisher's Exact Chi-square Test was applied to observe association between smoking and cognition. Level of significance was $p<0.05$.
\end{abstract}

Results: All PFT variables, compared between smokers and non-smokers yielded non-significant differences (VC: 3.97 (3.53-4.76) vs. 4.26 (3.83-4.66) p=0.709; $\mathrm{FEV}_{1}$ : 3.81 (3.47-4.71) vs. 4.17 (3.58-4.44) $\mathrm{p}=0.775 ; \mathrm{FEV} / \mathrm{FVC:} 98.09$ (95.72-99.09) vs. $95.3(92.5-98.2) \mathrm{p}=0.202)$. The comparison of MoCA score between the two groups (26(25-27) vs. $27(26-28) p=0.192$ as well as the association between smoking and cognition was non-significant.

Conclusion: Young healthy smokers without any pulmonary function abnormalities had cognition state similar to non-smokers. Therefore, there is no association of smoking on cognition in apparently healthy young adults.

Keywords: Cognition; Pulmonary function; Smoking

\section{Introduction}

Smoking status has been voiced as a risk factor for noncommunicable diseases, which is a prime cause of death and disability of millions of people year in and year out [1]. Nicotine is a potent addictive agent in cigarettes. Smokers link it to increased alertness, concentration and overall mental performance [2,3]. Whereas studies show gradual cognitive decline in smokers [4,5]. Montreal cognitive assessment (MoCA), a one-page, 30-point test administered in approximately 10 minutes, is a sensitive tool to assess even mild cognitive impairment [6]. Our study was aimed to shed some light on the controversies surrounding this matter.

\section{Methods}

The study was carried out at the Pulmonary Function Lab, Department of Basic and Clinical Physiology of BPKIHS. All procedures and experimental protocols were approved by the Institute's Ethical Review Board (BPKIHS, Dharan, Nepal). Informed written consent was obtained from all the participants.

The subjects $(n=46)$ were healthy young adult male medical students. Among them 23 were smokers and other 23 were nonsmokers. Mean age for smokers was 22 (21-22) years and that for nonsmokers was 21 (20-22) years respectively. Body mass index was under $25 \mathrm{~kg} / \mathrm{m}^{2}$. They neither were under any regular prescription medication nor had a history of drug/alcohol abuse.

The cardiovascular variables i.e, systolic blood pressure (SBP) and diastolic BP (DBP) were measured in the dominant hand in sitting position at rest. Then PFT was done using CHESTGRAPH HI101 spirometer system (Chest M.I., Inc, Tokyo, Japan). The variables taken into consideration in our study were vital capacity (VC), forced expiratory volume in first second $\left(\mathrm{FEV}_{1}\right)$ and ratio of forced expiratory volume in first second to forced vital capacity $\left(\mathrm{FEV}_{1} / \mathrm{FVC}\right)$. To measure these variables the subjects were instructed to inhale and exhale through the mouth, holding the disposable mouthpiece between the teeth. Nose-clips were used to ensure that the subject breathed entirely from the mouth. At first he had to inhale and exhale normally two times. Then he had to inspire maximally and expire forcefully so that all his expiratory muscles during forceful expiration were contracted. Then again he had to inhale and exhale normally. Emphasis was given on the maximum effort on behalf of the subject. The ambient temperature, age, sex, height, weight and race of the subject were measured and entered in the spirometer.

The nicotine dependence among smokers was assessed by Fragerstrom Test for Nicotine Dependence (FTND) questionnaire.

To assess cognitive function, Montreal Cognitive Assessment (MoCA) was used. The MoCA test is a one-page, 30-point test administered in approximately 10 minutes. The MoCA assesses several cognitive domains.

1. The short-term memory recall task (5 points) involves two learning trials of five nouns and delayed recall after approximately 5 minutes.

*Corresponding author: Karishma Rajbhandari Pandey, Department of Basic and Clinical Physiology, B.P. Koirala Institute of Health Sciences (BPKIHS), Buddha Road, Dharan, Nepal, Tel: +9779841377749, +09779862124700; E-mail: karishma@bpkihs.edu

Received February 23, 2017; Accepted March 27, 2017; Published March 31, 2017

Citation: Pandey KR, Panday DR, Sapkota N, Dhami A, Sarraf A, et al. (2017) Effect of Smoking in Cognition. J Pulm Respir Med 7: 399. doi: 10.4172/2161105X.1000399

Copyright: (c) 2017 Pandey KR, et al. This is an open-access article distributed under the terms of the Creative Commons Attribution License, which permits unrestricted use, distribution, and reproduction in any medium, provided the original author and source are credited. 
2. Visuospatial abilities are assessed using a clock-drawing task (3 points) and a three-dimensional cube copy (1 point).

3. Multiple aspects of executive functions are assessed using an alternation task adapted from the trail-making task ( 1 point), a phonemic fluency task (1 point), and a two-item verbal abstraction task (2 points).

4. Attention, concentration and working memory are evaluated using a sustained attention task (target detection using tapping; 1 point), a serial subtraction task ( 3 points), and digits forward and backward (1 point each).

5. Language is assessed using a three-item confrontation naming task with low-familiarity animals (lion, camel, rhinoceros; 3 points), repetition of two syntactically complex sentences ( 2 points), and the aforementioned fluency task.

6. Finally, orientation to time and place is evaluated (6 points).

For this assessment the examiner had to speak clearly, loudly and slowly. Before examining, the examiner briefed the instructions to the subject.

\section{Statistical analyses}

Statistical software SPSS ver.21 (SPSS INC., Chicago, ILL, USA) was used for statistical analysis. Since the data obtained was non Parametric, Mann Whitney U test was applied to compare the variables between the groups. Association was sought between smoking status and cognition scores using Fisher's Exact test.

\section{Results}

In our study, (Table 1) the smokers were found to be significantly older than control group. But there was no significant difference between the groups in terms of their BMI $(\mathrm{p}=0.104)$ and blood pressure (SBP $\mathrm{p}=0.082$, DBP $\mathrm{p}=0.644$ ). The pulmonary function assessed between the groups showed decreased $\mathrm{VC}$ and $\mathrm{FEV}_{1}$ in smokers but was not statistically significant (Table 2 ). $\mathrm{FEV}_{1} / \mathrm{FVC}$ ratio was increased in smokers, though it was also not significant statistically (98.09 (95.7299.09) vs. 95.3 (92.5-98.2) $\mathrm{p}=0.202)$. The MoCA score was reduced in smokers (Table 2). However it was not statistically significant $(\mathrm{p}=0.192)$

In our study 11 of the smokers and 5 of the non- smokers had failed in the MoCA (Table 3). Those failed had a score in the range of 22-25. Their score placed them into the category of mild cognitive impairment. Eighteen of the control subjects and 12 smokers had score $>26$. Ten of the control and 8 of the smokers had scored at the range of 26-27. A score of 28-29 was secured by 7 of the control and only 4 of the smokers. None of the smokers secured full marks 30, whereas only one of the controls was able to score full marks. The association between smoking status and cognition score was assessed using Fischer's Exact test. It showed no association (Table 4). Linear Regression analysis was done to observe if age is a confounder for the MoCA score as shown in Table 5 . The $\mathrm{p}=0.117$ showed no significant correlation between age and the MoCA score.

\begin{tabular}{|c|c|c|c|}
\hline Variable & $\begin{array}{c}\text { Smoker } \\
\text { Median(IQR) }\end{array}$ & $\begin{array}{c}\text { Control } \\
\text { Median(IQR) }\end{array}$ & P Value \\
\hline Age (years) & $22(21-22)$ & $21(20-22)$ & $\mathbf{0 . 0 0 1}$ \\
\hline $\mathrm{BMI}\left(\mathrm{Kg} / \mathrm{m}^{2}\right)$ & $23.53(22.4-25.7)$ & $22.09(20.5-25.3)$ & 0.104 \\
\hline $\mathrm{SBP} \mathrm{mmHg}$ & $120(120-130)$ & $120(120-120)$ & 0.082 \\
\hline $\mathrm{DBP} \mathrm{mmHg}$ & $80(70-80)$ & $80(70-80)$ & 0.644 \\
\hline
\end{tabular}

BMI: Body Mass Index; SBP: Systolic Blood Pressure; DBP: Diastolic Blood Pressure. $p<0.05$ is statistically significant.

Table1: Comparison of anthropometric and cardiovascular variables in smoker and non-smoker.

\begin{tabular}{|l|c|c|c|}
\hline Variable & \multicolumn{1}{|c|}{$\begin{array}{c}\text { Smoker } \\
\text { Median(IQR) }\end{array}$} & $\begin{array}{c}\text { Control } \\
\text { Median(IQR) }\end{array}$ & P Value \\
\hline Pulmonary Function & \multicolumn{3}{|l|}{} \\
\hline VC (liters) & $3.97(3.53-4.76)$ & $4.26(3.83-4.66)$ & 0.709 \\
\hline FEV (litres) & $3.81(3.47-4.71)$ & $4.17(3.58-4.44)$ & 0.775 \\
\hline FEV $/$ FVC & $98.09(95.72-99.09)$ & $95.3(92.5-98.2)$ & 0.202 \\
\hline MoCA & $26(25-27)$ & $27(26-28)$ & 0.192 \\
\hline Cognitive Score & 26) &
\end{tabular}

VC: Vital Capacity; FEV : Forced Expiratory Volume in $1^{\text {st }}$ sec, FEV /FVC: Ratio Of Forced Expiratory Volume in $1^{\text {st }}$ sec to Forced Vital Capacity, $p<0.05$ is statistically significant

Table 2: Comparison of pulmonary function test and MoCA variables in smoker and non-smoker.

\begin{tabular}{|l|c|c|c|c|c|c|c|c|c|c|}
\hline Groups & \multicolumn{10}{|c|}{ MoCA score } \\
\hline & 22 & 23 & 24 & 25 & 26 & 27 & 28 & 29 & 30 & Total \\
\hline Control & 0 & 2 & 1 & 2 & 6 & 4 & 4 & 3 & 1 & 23 \\
\hline Smoker & 1 & 1 & 1 & 8 & 1 & 7 & 3 & 1 & 0 & 23 \\
\hline
\end{tabular}

Table 3: Comparison of individual MoCA score between smoker and non-smoker.

\begin{tabular}{|c|c|c|c|}
\hline Cognitive Status & Smoker & Control & P value \\
\hline Normal Cognition & 12 & 18 & 0.063 \\
\hline Mild Cognitive Impairment & 11 & 5 & \\
\hline
\end{tabular}

Table 4: Fisher's Exact Test showing association between smoking status and cognitive status.

\begin{tabular}{|c|c|}
\hline \multirow{2}{*}{ Dependent Variable } & Independent Variable \\
\cline { 2 - 2 } MoCA Score & Age ( $\mathrm{p}$ value $)$ \\
\hline
\end{tabular}

Table 5: Linear regression analysis between age and MoCA score.

\section{Discussion}

As medicine is advancing more and more research and studies are co-relating between smoking and various disease conditions [1]. Impact of smoking on respiratory and cardiovascular system has been well established along with smoking being the risk factor in almost every disease entity we study [7]. Our study was aimed to find out the relation between smoking status and cognition.

The BMI, CVS variables and pulmonary variables between the smokers and control were not significantly different. Smokers in our study population were mildly nicotine dependent and were of younger age group, hence no adverse effect of smoking was evident in the cardiovascular and pulmonary functions. The smokers in our study population were older than the control group. Age adjustment was done with regression analysis which showed age did not affect cognition score.

Smoking is associated with entry of nicotine and other components such as anabasine and anatabine in the body. These substances are considered to improve cognition in terms of memory and attention [8]. In our set up the cognition was assessed using Montreal cognitive assessment. Our study did not show any association of smoking and cognition. This is in line with the research done by Kalmijn [9] and Ernst [10]. Whereas Dr. Chandresh Dumatar showed definite improvement in memory with smoking [11]. While Vajravelu HR and Robert D Hill showed decreased cognitive performance in young adult smokers $[7,12]$. Other studies were done in older population where smoking has been associated with decline in cognition $[13,14]$. Smokers with positive respiratory disorders were linked with decline in cognition. Since our 
study subjects were young and without any respiratory disorders we did not obtain decline in cognition with smoking.

Since in our study we found no association of smoking with cognition as the level of significance is 0.063 , we reject our null hypothesis.

\section{Limitations of the Study}

1. The study population was small.

2. Study group did not include moderate, high and severe nicotine dependent groups.

\section{Conclusion}

The pulmonary function test of mild nicotine dependent smokers and control group were comparable. Their smoking status yielded no association with cognition.

\section{Acknowledgements}

We are thankful to all the members of Department of Basic and Clinical Physiology, Dr. Shrijana Dahal, Department of Community Dentistry and Mr D. B. Baral, Department of Community Medicine including all participants for successful conduction of the study.

\section{References}

1. Ministry of Health and Population [Nepal]: Tobacco Control Reference Book. Kathmandu: Ministry of Health and Population; 2011.

2. Elrod K, Buccafusco JJ, Jackson WJ (1988) Nicotine enhances delayed matching-to-sample performance by primates. Life Sci 43: 277-287.

3. Salomon AR, Marcinowski KJ, Friedland RP, Zagorski MG (1996) Nicotine inhibits amyloid formation by the beta-peptide. Biochemistry 35: 13568-13578.
4. Anstey KJ, von Sanden C, Salim A, O'Kearney R (2007) Smoking as a risk factor for dementia and cognitive decline: a meta-analysis of prospective studies. Am J Epidemiol 166: 367-378.

5. Cervilla JA, Prince M, Mann A (2000) Smoking, drinking, and incident cognitive impairment: a cohort community based study included in the Gospel Oak project. J Neurol Neurosurg Psychiatry 68: 622-626.

6. Nasreddine ZS, Phillips NA, Bédirian V, Charbonneau S, Whitehead V, et al (2005) The Montreal Cognitive Assessment (MoCA): A brief screening tool for mild cognitive impairment. J Am Geriatr Soc 53:695-699.

7. Vajravelu HR, Gnanadurai TK, Krishnan P, Ayyavoo S (2015) Impact of quantified smoking status on cognition in young adults. J Clin Diagn Res 9: CC01-CC03.

8. Levin ED, Hao I, Burke D, Cauley M, Hall BJ, Rezvani AH (2014) Effects of tobacco smoke constituents, anabasine and anatabine, on memory and attention in female rats. J Psychopharmacol 28: 915-922.

9. Kalmijn S, van Boxtel MP, Verschuren MW, Jolles J, Launer LJ (2002) Cigarette smoking and alcohol consumption in relation to cognitive performance in middle age. Am J Epidemiol 156: 936-944.

10. Ernst M, Matochik JA, Heishman SJ, Van Horn JD, Jons PH, et al. (2001) Effect of nicotine on brain activation during performance of a working memory task. Proc Natl Acad Sci U S A 98: 4728-4733.

11. Dumatar C, Chauhan J (2011) A study of the effect of cigarette smoking on cognitive parameters in human volunteers. Natl J Integr Res Med 2: 71-76.

12. Hill RD, Nilsson LG, Nyberg L, Bäckman L (2003) Cigarette smoking and cognitive performance in healthy Swedish adults. Age Ageing 32: 548-550

13. North TL, Palmer TM, Lewis SJ, Cooper R, Power C, et al. (2015) Effect of smoking on physical and cognitive capability in later life: a multicohort study using observational and genetic approaches. BMJ Open 5: e008393.

14. Yin $P, M a ~ Q$, Wang L, Lin P, Zhang $M$, et al. (2016) Chronic obstructive pulmonary disease and cognitive impairment in the Chinese elderly population: A large national survey. Int J Chron Obstruct Pulmon Dis 11: 399-406. 